\title{
LA VIDA EN LA CASA DE MISERICORDIA DE PALMA DURANTE EL SIGLO XVIII: CAMBIOS Y CONTINUIDADES
}

\section{Life in the "Casa de Misericordia" of Palma during the Eighteenth Century: Changes and Continuities}

\author{
Francisco José GARCÍA PÉREZ \\ Universitat de les Illes Balears/IEHM \\ fj.garcia@uib.es
}

Fecha de recepción: 5/04/2017

Fecha de aceptación definitiva: 8/06/2017

RESUMEN: Actualmente contamos con distintos artículos relacionados con las casas de Misericordia, instituciones de caridad que tuvieron gran importancia durante el siglo XVIII. Sin embargo, todavía no hay prácticamente estudios que analicen la vida dentro de estos hospicios. Por ello, este artículo pretende estudiar la vida dentro de la casa de Misericordia de Palma, especialmente después de las reformas del año de 1799, que marcaron un nuevo comienzo. Aquí se estudiará el modo de vida de los pobres, los distintos empleados que dirigían la Misericordia y, finalmente, los castigos que se utilizaban para mantener el control social.

Palabras clave: Casa de Misericordia; Mallorca; beneficencia; Ilustración.

ABSTRACT: At the moment there exist different articles, relating to the "casas de Misericordia", institutions of charity that had great importance during the eighteenth century. However, there are still practically no studies that analyze life within these hospices. For this reason, this article aims to study life in the "casa de Misericordia" of Palma, especially after the reforms of the year 1799, which marked a new beginning. We will study the way of life of the poor people, the different employees who directed the Misericordia and, finally, the punishments that were used to maintain social control.

Key words: Casa de Misericordia; Majorca; charity; Enlightenment. 
Durante las últimas décadas del siglo xx, el estudio de las casas de Misericordia cobró un enorme interés en la historiografía española ${ }^{1}$. El desarrollo de nuevas líneas de investigación centradas en el análisis de la pobreza, sectores socialmente marginales e instituciones de beneficencia a lo largo de la Edad Moderna se ha traducido en trabajos realmente interesantes. Sin embargo, muchos de estos trabajos dejan de lado un aspecto fundamental de dichas instituciones, y es la vida dentro de sus dependencias. La mayoría de contribuciones en este ámbito han centrado su atención mayormente en cuestiones de aspecto económico, como puedan ser las fábricas adheridas a los hospicios o las retribuciones que se obtenían para mantenerlos, obviando, por tanto, el día a día de los pobres internos.

En lo que se refiere a la casa de Misericordia de Palma, solo recientemente contamos con algunas aportaciones, si bien la mayoría se centran en los momentos posteriores a la gran reforma que esta experimentó en 1799. La Misericordia del siglo XVIII sigue pendiente de un análisis exhaustivo, y más cuando contamos con fuentes documentales de gran interés, que ofrecen información muy relevante sobre la vida diaria en aquel hospicio a lo largo del Setecientos. Primeramente, el Arxiu del Regne de Mallorca (ARM) conserva las actas de la junta de gobierno desde que esta comenzó a funcionar en 1799, además de documentación de muy diversa índole con datos significativos sobre el día a día en el hospicio. Asimismo, las actas municipales conversadas en el Arxiu Municipal de Palma (AMP), como patrón incuestionable de la Misericordia, ayudan a conocer las políticas del Ayuntamiento de Palma para hacer más cómodo el internamiento de los pobres. Pero

1. Actualmente contamos con distintos trabajos que analizan las llamadas casas de Misericordia: PAlOMARES IBÁÑEZ, Jesús. La asistencia social en Valladolid. El Hospicio de pobres y la Real Casa de Misericordia (1724-1847). Valladolid: Diputación Provincial Valladolid, 1975; MARTínez Veron, Jesús. La Real Casa de Misericordia de Zaragoza. Vols. I, II. Zaragoza: Diputación Provincial de Zaragoza, 1985; Carbonell i Esteller, Montserrat. Sobreviure a Barcelona. Dones, pobreza i assistència al segle XVIII. Barcelona: Eumo, 1997; AlOnSO, Anna y RoDRíguEZ, Lluïsa. "Beneficència il-lustrada i iniciatives econòmiques a la casa de Misericòrdia de Barcelona al llarg de la segona meitat del segle XVIII». Pedralbes, 2003, 23, pp. 797-824; Alonso, Anna y RoDríguez, Lluïsa. "Dones i formació ocupacional en la segona meitat del set-cens: de la Casa de Misericòrdia a l'Hospici General. Utopia i realitat». Barcelona. Quaderns d'Història, 2002, 7, pp. 235-249; PAGÁn, Ester Alba. "Papel de la Iglesia en la historia y construcción de una institución asistencial valenciana: el caso de la Casa de Misericordia”. En CAMPOS Y FERNÁNDEZ DE SEVILla, Francisco Javier (coord.). La Iglesia española y las instituciones de caridad. San Lorenzo de El Escorial: Ediciones Escurialenses, 2006, pp. 396-426; LóPEz GARCíA, María Trinidad. "Aproximación a la gestión municipal del Real Hospicio y Casa de Misericordia de Murcia en el último tercio del siglo XVIII: las temporalidades de los jesuitas». En CAmpos y FernándeZ DE SEviLLA, Francisco Javier (coord.). La Iglesia española y las instituciones de caridad. San Lorenzo de El Escorial: Ediciones Escurialenses, 2006, pp. 427-456; DEYÀ BAuZÀ, Miquel. "Assistència social a Mallorca durant l'Antic Règim». En PASCuAl, Aina (coord.). De la beneficència a l'Estat del benestar. Història dels serveis socials a Mallorca (segles XVI-XX). Palma: Ajuntament de Palma, 2010, pp. 13-51; BARRIO MoYA, José Luis. "El Real Hospital de la Misericordia de Madrid según un inventario de 1735». Anales del Instituto de Estudios Madrileños, 51, 2011, pp. 137-147; CAPELO, Mariló. "La contabilidad de una organización benéfica en tiempos de la Ilustración. El hospicio "Casa de Misericordia" de Cádiz (1784-1790)». De Computis, 2014, 20, pp. 7-36. 
además, el Archivo Histórico Nacional (AHN) conserva muchos expedientes de distintas casas de Misericordia repartidas por todo el territorio español.

En síntesis, este artículo pretende ofrecer un análisis de la vida diaria en un hospicio del siglo XVIII. Partiendo de la reforma de 1799 como punto de referencia, se observarán los distintos ámbitos que afectaban a la vida diaria del hospicio, como pueden ser su infraestructura, el personal doméstico y las actividades asignadas a los mismos pobres. Además, se pondrá especial énfasis en remarcar cuáles fueron los cambios que se implantaron en consonancia con las políticas ilustradas de Carlos III, y qué se mantuvo intacto, bien porque funcionaba ya, o porque fue demasiado difícil de extirpar.

\section{La casa de la Misericordia de Palma en el CONTexto Del Reformismo BORBÓNICO}

A lo largo de la Edad Moderna, la isla de Mallorca contó con distintos hospicios, destinados cada uno de ellos a unas necesidades específicas ${ }^{2}$. El asunto de los pobres había sido una cuestión siempre pendiente, y su presencia en la ciudad de Palma y en las villas rurales nunca se había interrumpido ${ }^{3}$. De hecho, la difícil situación económica que vivió la isla en distintos momentos del siglo XVIII, únicamente acentuó el número de mendigos y desamparados ${ }^{4}$. Hasta tal punto era así, que las redes de beneficencia existentes terminaron obsoletas. Entre estas instituciones de caridad, siempre había refulgido con mayor fuerza la casa de la Misericordia. Fundada en 1677 por el jesuita Ignacio Fiol, había nacido precisamente "para recoger a todos los mendigos que, por su ancianidad, sus achaques, su vaguedad, u otro vicio o defecto corporal, eran inhábiles o inútiles para trabajar y ganarse su subsistencia" ${ }^{5}$. Se trataba de un heterogéneo espectro de internos, que incluía a mujeres y hombres de edad adulta -con especial predilección por ancianos desamparados-, pero también a niños y niñas pequeños. Con sus constituciones aprobadas, comenzó a funcionar muy pronto, siempre bajo el amparo de las instituciones civiles y religiosas de Mallorca ${ }^{6}$.

Los primeros años de la Misericordia fueron ciertamente difíciles. Desde un principio, el hospicio se sustentó en las limosnas para poder continuar activo. Pero lo cierto es que la recolección de dádivas no era sencilla en la Mallorca de finales

2. Moll Blanes, Isabel. "Hospitales y hospicios en Mallorca en el siglo XVIII". En ABreU, Laurinda (ed.). Asistencia y caridad como estrategias de intervención social: Iglesia, Estado y Comunidad (siglos $X V-X X)$. Bilbao: Servicio de Publicaciones Universidad del País Vasco, 2007, pp. 57 y ss.

3. Para una visión global del fenómeno de la pobreza durante la Edad Media, véase Woolf, Stuart. Los pobres en la Europa Moderna. Barcelona: Crítica, 1989.

4. DeyÀ BauŻ̀, Miquel. "Assistència social a Mallorca", op. cit., p. 27.

5. Arxiu del Regne de Mallorca (ARM), Misericordia, M 8, s/f.

6. Véase Rullán, José. "Noticias para servir a la historia eclesiástica de Mallorca". Bolletí de la Societat Arqueològica Lul.liana, 1926, 31, pp. 30-41. 
del siglo XVII. Dejando de lado que otras instituciones, como el Hospital General, también sobrevivían con estos ingresos ${ }^{7}$, la precaria situación económica y social que se vivió por aquel entonces, únicamente sirvió de freno. Pues mientras la Misericordia se veía cada vez más falta de recursos económicos, el número de pobres en Palma y los alrededores no dejaba de crecer. De hecho, en 1705, el Gran i General Consell escribió a los bailes de las distintas villas de Mallorca recordándoles lo desesperado de la situación que vivía la Misericordia, especialmente ante el "gran el número de pobres, y necessitat que en aquella casa se trova, sense tenir més remei que de las limosnas, que van recullint per tot lo Regne» ${ }^{8}$.

Durante todo el siglo XVIII hubo algunos intentos de revitalizar el hospicio, si bien terminaron en fracaso. La mayoría de las veces, se buscaron soluciones para la deficiente red de recaudación de limosnas, siempre insuficientes. Por aquel entonces, las distintas villas rurales contaban con bacineros contratados por la Misericordia, que pedían donativos destinados al hospicio. Dado que la urgencia de estos era tan desesperada, en 1723, el Ayuntamiento de Palma escribió al capitán general para que "se sirviese conceder exención de cargos, oficios y guardias a los bacineros de dicha casa" ${ }^{9}$, precisamente con la intención de que se dedicasen únicamente a su tarea. Todo ello, sin embargo, no consiguió mejorar la situación. La Misericordia continuó en unas condiciones poco propicias para el mantenimiento de los pobres allí residentes, y las demandas de ayuda remitidas al Ayuntamiento de Palma siguieron siendo recurrentes, aunque no siempre contestadas.

Hubo que esperar al último tercio del siglo XVIII para constatar un renovado interés por el estado de la Misericordia. Fue precisamente bajo el reinado de Carlos III cuando se retomaron los proyectos de reformar aquel hospicio decadente ${ }^{10}$. Si la pobreza había sido un problema público durante los siglos precedentes, con este monarca asumió una importancia todavía mayor ${ }^{11}$. Siempre amparado en sus ministros, Carlos III desarrolló políticas firmemente represoras que perseguían un doble fin: primeramente, conseguir el máximo recogimiento de pobres, liberando a las ciudades de estos elementos considerados «inútiles» a los intereses del

7. Sobre el Hospital General véase COnTRERAs Mas, Antonio. «Enfermos del Hospital General de Mallorca a fines del siglo XV». Medicina Balear, 2012, 27/3, pp. 48-57; SANTAMARía ArándeZ, Álvaro. "La asistencia de los pobres en Mallorca en el bajo Medievo». Anuario de Estudios Medievales, 1983, 13, pp. 3981-406.

8. Arxiu del Regne de Mallorca (ARM), Audiencia, AA 666, s/f.

9. ARM, Audiencia, AA 666, s/f.

10. MAZA Zorrilla, Elena. Pobreza y asistencia social en España. Siglos XVI al XX. Valladolid: Secretariado de Publicaciones de la Universidad de Valladolid, 1987, p. 109.

11. Véase JORI, Gerard. "La política de la salud pública en el pensamiento ilustrado español. Principales aportaciones teóricas». Scripta Nova, 2012, XVI/418, pp. 1-29. 
Estado $^{12}$; y, al mismo tiempo, la reconversión de estos hospicios en fábricas de producción, que ofreciesen a los allí residentes una formación ${ }^{13}$.

Bajo la órbita de estas reformas ilustradas que irradiaban desde la Corte de Madrid, las redes de beneficencia existentes adquirieron una importancia caudal, y se programó la construcción de nuevos hospicios y hospitales ${ }^{14}$. Las casas de Misericordia se convirtieron en una constante en la mayoría de ciudades españolas, y las autoridades civiles y religiosas asumieron un patronazgo todavía mayor. En muchos lugares, los respectivos Ayuntamientos se comprometieron a liderar estas instituciones, cumpliendo con las políticas de salud pública y recogimiento de pobres ${ }^{15}$. En otros, fueron precisamente los obispos quienes asumieron esta difícil tarea.

Para el mejor gobierno de estas renovadas casas de Misericordia, se diseñaron juntas formadas por representantes de todos los estamentos ${ }^{16}$. La mayoría de las juntas de gobierno únicamente diferían en la proporción de miembros seculares y del clero. Por ejemplo, mientras la casa de Misericordia de Tolosa, en Guipúzcoa, contaba con mitad y mitad $^{17}$, «incluyendo precisamente al señor vicario entre las primeras, porque por su ministerio sabe mejor que otro alguno las necesidades del Pueblo» ${ }^{18}$, otras como las de Cádiz, Barcelona o Valencia priorizaban el papel de

12. En muchos sentidos, el motín de Esquilache en 1766 radicalizó la visión de Carlos III hacia los sectores marginales de la sociedad. Las ciudades estaban amasadas de mendigos que las recorrían suplicando limosna, y se convertían en elementos "inútiles», pues no producían. De modo que, a partir de entonces, se vivió una verdadera cacería de pobres, con el objetivo preciso de eliminar esta lacra social, como eran considerados para la Corona. De modo que las décadas de los ochenta y noventa del siglo XVIII estuvieron repletas de reales órdenes que mandaban la reclusión de todos los pobres en las casas de Misericordia, con la consecuente reforma de las mismas para poder acoger a tal número de personas. Ramos VÁzQuez, Isabel. «Policía de vagos para las ciudades españolas en el siglo XVIII». Revista de Estudios Histórico-Jurídicos, 2009, 31, p. 230.

13. Alonso, Anna y Rodríguez, Lluïsa. "Beneficència il-lustrada», op. cit., p. 802.

14. Trinidad FERnÁNDEZ, Pedro. "Asistencia y previsión social en el siglo XVIII". Servicios Sociales y Politica Social, 1985, 2, p. 2.

15. Martínez Domínguez, Luis Manuel. «Función educativa de los hospitales y hospicios en España hasta la primera mitad del siglo XIX. La Cuna de Expósitos en las Palmas de Gran Canaria: de la respuesta socioeducativa a la lucha por la supervivencia». En BERRUEZO AlBÉNIZ, María Reyes y CONEjERO LóPEz, Susana (coords.). El largo camino hacia una educación inclusiva: la educación especial y social del siglo XIX a nuestros días. Pamplona-Iruñea: Universidad Pública de Navarra, 2009, vol. 2, p. 226.

16. Véase Palomares IbÁÑEZ, Jesús. La asistencia social en Valladolid..., op. cit., p. 91.

17. Una de las mayores variantes en lo que respectaba a las juntas administradoras era el papel que el obispo jugaba. En algunas, la presencia episcopal era enorme, como en la casa de Misericordia de Valencia, donde el arzobispo Fuero y Fabián intervino de forma activa a través de un representante y canónigo. Sin embargo, en otras casas de Misericordia, como la de Gerona, el obispo se quejó al Consejo de Castilla «a causa de no habérsele dado la presidencia de ella, como era regular y conforme en semejantes fundaciones». Los conflictos entre obispos y Ayuntamientos fueron muchos con respecto a estas instituciones. Archivo Histórico Nacional (AHN), Consejo, L. 1946, f. 41.

18. Fundación Sancho el Sabio (FSS), Constituciones de la casa de Misericordia de Tolosa, s/f. 
los regidores municipales para el gobierno de la institución ${ }^{19}$. Estas juntas pretendían ejercer un control todavía mayor sobre estos centros, rompiendo con décadas de olvido y decadencia en el ámbito asistencial. Y como cabía esperar, estas ansias reformadoras llegaron también a la casa de Misericordia de Palma.

En 1772, el Ayuntamiento de Palma y el obispo se unieron para dotar a la Misericordia de una junta a imagen de lo que estaba ocurriendo en otros territorios: «El Iltmo. Sr. Obispo, nombrará los eccos. y la Ciudad los seculares» ${ }^{20}$. A continuación, se envió a un canónigo de la Catedral para que revisase el estado de la infraestructura del hospicio, proponiendo las reformas que considerase necesarias. Sin embargo, pronto crecieron las disputas en torno al proyecto asistencial ${ }^{21}$. Primeramente, el obispo consideraba que la Misericordia era poco más que una ruina inhabitable, y que existían otros lugares más apropiados para alojar a los pobres $^{22}$. Al mismo tiempo, las discordias de jurisdicción y precedencia entre el prelado y el Cabildo eclesiástico en nada ayudaron. Así que, finalmente, el proyecto asistencial terminó en una nebulosa, y mientras que en todo el territorio español se experimentaban grandes reformas destinadas a la mejora de las casas de Misericordia, la de Palma continuó como hasta entonces. Pero, además, a esto había que sumarle el ambiente de malestar económico y social que se vivió a finales del siglo XVIII, con cosechas desastrosas y sequías que presagiaban periodos de hambrunas ${ }^{23}$; o lo que es lo mismo, un imparable aumento de los mendigos.

Durante la década de los noventa, el estado de la Misericordia era ya deplorable. El edificio no contaba con las infraestructuras necesarias para alojar adecuadamente a los residentes, y los que allí vivían estaban en condiciones muy precarias $^{24}$. El mismo obispo Pedro Rubio-Benedicto se había ofrecido ya en 1781 a costear una reforma del edificio, "por ser necesarias tres piezas más, y algunas otras oficinas para la comodidad, salud y habitación del crecido número de pobres de ambos sexos que hay en ella recogidos ${ }^{25}$. Dicha reforma nunca se materializó

19. CAPELO, Mariló. "La contabilidad de una organización benéfica», op. cit., pp. 7-36.

20. ARM, Audiencia, AA, 752/1, s/f.

21. García PÉrez, Francisco José. «Represión académica en la Mallorca del siglo XVIII. El obispo Juan Díaz de la Guerra y la clausura el colegio de la Sapiencia en 1773». Chronica Nova, 2015, 41, p. 202.

22. Véase Arxiu Municipal de Palma (AMP), Actas Municipales, AH 2100/2, s/f.

23. JuAN VIDAL, Josep. "Las crisis agrarias y la sociedad en Mallorca durante la Edad Moderna". Mayurqa, 1976, 16, p. 111; JUAN VIDAL, Josep. "La evolución de la producción agrícola en Mallorca durante la Edad Moderna. Fuentes y problemas de su estudio". Moneda y Crédito, 1978, 145, pp. 67-100.

24. Todo indica que la situación de la Misericordia era desesperada. A la falta reiterada de víveres para la manutención de los internos, se le sumaban las condiciones insalubres que, parece ser, se respiraban en el hospicio. En un registro de pobres que se ha conservado entre los años 1793 y 1799, se puede observar como muchos de los pobres que entraron en la Misericordia murieron a las pocas semanas, lo que puede deberse tanto a las condiciones propias de los que ingresaban, como a la situación que allí se encontraban. ARM, Misericordia, 461.

25. AMP, Actas Municipales, AH 2107, f. 464. 
debido al constante desacuerdo entre el Ayuntamiento y el prelado. Pero además, en 1789, "se acabaron las provisiones de trigo, legumbres y dinero" ${ }^{26}$.

De modo que, años después, y como iniciativa del Ayuntamiento de Palma y el obispo Bernat Nadal -que llegó a Mallorca en 1796-, se planteó una reforma contumaz de la Misericordia ${ }^{27}$. La idea era dotarla de una junta de gobierno, aumentando los fondos asignados a la institución, y todavía más importante, desarrollando nuevas políticas para encerrar allí a todos los pobres de Palma y las villas rurales ${ }^{28}$. De ese modo, comenzó una reforma que se había retrasado ya más de veinte años.

La llamada "Junta de Gobierno de la Casa de Misericordia que acaba de nombrar el Ayuntamiento ${ }^{29}$ estaba presidida por el corregidor del Consistorio de Palma, y la integraban catorce miembros más: representantes del Cabildo, las parroquias, la nobleza y los gremios ${ }^{30}$. Para consolidar el desarrollo económico de la Misericordia, la junta planteó tres grandes reformas necesarias. Primeramente, se centró en la remodelación de sus infraestructuras, comenzando por el mismo edificio. Hasta ese momento, decía el fiscal de la Real Audiencia, «el edificio en lo material está tan ruinoso, que no se puede mirar sin horror; y que si se ha de establecer en él el hospicio, es preciso derribarlo y construirlo nuevamente ${ }^{31}$. Aunque esta información no era del todo cierta, el hospicio sí necesitaba de una urgente remodelación y reforma. De modo que, ese mismo año de 1799, se prepararon las obras y se compraron las casas vecinas, pues «su situación permite poderse extender con facilidad y poco desembolso por el lado del hospital, y sin ninguno por el de la Rambla, tomando algo de terreno que sirve de desahogo o salida ${ }^{32}$. Como la idea era recoger al mayor número de pobres posible, era necesario que hubiera habitaciones suficientes, así como estancias donde aislar a los enfermos.

26. ARM, Misericordia, M 8, s/f.

27. Sobre una biografía del obispo de aquel momento, el mallorquín Bernat Nadal i Crespí, véase Barrio Moya, José Luis. "Don Bernat Nadal i Crespí, obispo de Mallorca entre 1794 y 1818". Bolletí de la Societat Arqueològica Lul-liana, 2003, 59, pp. 359-364; Duran Pastor, Miquel. Bernat Nadal $i$ Crespí. Un bisbe solleric que fou diputat a les Corts de Cadis. Palma: Ajuntament de Palma, 1986.

28. Deyà BauŻ̀, Miquel. "Assistència social a Mallorca", op. cit., p. 27.

29. ARM, SEMAP, caja 4/2, s/f.

30. En concreto, sus primeros miembros fueron los siguientes: "Los caballeros regidores del Santo Hospital, el M. Ilustre Sr. Don Valentín de Grimarest, corregidor de esta Ciudad y su término con los señores Don Josep Zanglada de Togores, y Don Josep Cotoner, regidores de la presente Ciudad; Don Jaime Terrasa, pro. y arcediano de la Santa Iglesia Catedral, Don Onofre Barceló, pro. canónigo de la misma Santa Iglesia, Don Juan Barceló, cura párroco de la Iglesia de Sant Eulalia, Don Antonio Llaneras, pro. cura párroco de la iglesia de San Nicolás, los caballeros Josef Desbrull y don Tomas de Verí, Don Bernardo Contesti, abogado, Don Josef Barceló, médico, Don Miguel Barbarin y Don Antonio Gia, comerciantes, Don Pedro Juan Muntaner hornero, y don Ramon Moragues». ARM, Misericordia, M 1, p. 1.

31. Biblioteca Bartomeu March (BBM), Fondo del Convento de San Francisco, leg. 6, s/f.

32. ARM, Misericordia, M 1, s/f. 
A continuación, otro de los grandes objetivos de la junta era confeccionar una red de donativos que llegasen ininterrumpidamente al hospicio. Teniendo presente que el porvenir de la Misericordia seguía dependiendo de las limosnas, se crearon juntas de caridad, que estaban distribuidas por las principales parroquias de Palma y puntos clave de las áreas rurales de la isla ${ }^{33}$. Dirigidas por un cura párroco, su vicario y sacristán, y algunos vecinos, tenían la misión de recoger limosnas semanalmente y destinarlas al sostenimiento del hospicio, así como «tener un perfecto conocimiento de los pobres necesitados, de la clase de vergonzantes y jornaleros necesitados de la parroquia " ${ }^{34}$.

La idea de mantener un control más severo de los pobres se ligaba, precisamente, con el tercer gran objetivo de la junta. Coincidiendo con los intereses de la monarquía carolina, todos los pobres debían pasar a vivir en estas casas de Misericordia y dejar de mendigar en las calles ${ }^{35}$. Desde mediados del siglo XVIII, una serie de Reales Órdenes habían limitado la demanda de limosnas, "teniendo presentes los excesos y abusos que cometían las personas que andaban vagantes por el Reino [...], los engaños artificiosos que practicaban para recoger limosnas ${ }^{36}$. Para evitar esta situación, primeramente la Corona había optado por conceder licencias de limosnas, diferenciando a los pobres «verdaderos" de aquellos conocidos como vergonzantes, y que simplemente se valían de artificios para negarse a trabajar. Sin embargo, finalmente, se optó por el recogimiento total de todos los pobres sin distinción. La Misericordia de Mallorca no fue menos contumaz en este ámbito.

Tras las reformas de 1799, fueron muchas las modificaciones que se produjeron. La nueva junta de gobierno alteró las constituciones y reelaboró la mayoría de puntos referentes al día a día del hospicio ${ }^{37}$. Con su interés puesto en ejercer un mayor control sobre la vida diaria de la Misericordia, sus miembros examinaron las necesidades y posibilidades para mejorar dicha institución. Y lo cierto es que estas transformaciones se movieron siempre entre el cambio y la continuidad, intentando mantener aquello que funcionaba y eliminando todos los elementos que venían arrastrándose desde su fundación e impedían una mejora definitiva de la

33. Sobre estas juntas de caridad y sus características, véase RAmos VÁZQUEZ, Isabel. "Policía de vagos para las ciudades españolas", op. cit., p. 252.

34. ARM, Misericordia, M 8, s/f.

35. Una Real Cédula dada en 1781 establecía que "los vagos ineptos para las armas por defecto de talla o de robustez, y lo que no tengan la edad de diez y siete años, o hayan pasado de la de treinta y seis, [...], se deben recoger igualmente y dárseles destinos para el servicio de la Armada, Oficios, o recogimientos en Hospicios y Casas de Misericordia, u otros equivalentes». Estas políticas sociales pretendían eliminar todos aquellos elementos inútiles, de modo que aquellos que se negasen a trabajar fueron enviados al ejército, las mujeres licenciosas a las casas de recogimiento y, en el caso de los pobres, a las casas de Misericordia. AMP, copia de Real Cédula de 1781, AH 2106/1, s/f.

36. ARM, Audiencia, Real Acuerdo, 754/6, f. 1.

37. Esto mismo ocurrió en otras casas de Misericordia que se reformaron a fines del siglo XVIII, véase Palomares IbaÑez, Jesús María. La asistencia social en Valladolid..., op. cit., p. 91. 
Misericordia. Si finalmente se consiguieron los objetivos planteados, es algo que no ha quedado del todo claro.

\section{LA ORGANIZACIÓN Y EL PERSONAL DE LA CASA DE MiseriCORDiA}

Desde sus inicios en 1677, la Misericordia contó con un cuerpo de trabajadores encargados de las tareas cotidianas dentro de sus muros. Hasta la reformas de fines del siglo XVIII, fueron muy pocas las modificaciones que vivió el organigrama del hospicio. La dirección de la Misericordia recayó, hasta 1799, en un superintendente, encargado de todos los gastos del hospicio, y un mayordomo, que supervisaba las labores que se asignaban a los mismos pobres ${ }^{38}$. Ambos respondían únicamente ante el Gran i General Consell y, tras los decretos de Nueva Planta, ante cuatro regidores del Ayuntamiento de Palma que iban rotando cada dos años ${ }^{39}$. Pero teniendo en cuenta el desinterés que mostraron las instituciones de poder, es plausible pensar que superintendente y mayordomo asumieron una autoridad bastante amplia en todo lo que afectaba al hospicio.

Conforme fue avanzando el siglo XVIII, la figura del superintendente terminó desapareciendo ${ }^{40}$. Es difícil saber exactamente cuándo ocurrió, pero lo que está claro es que la junta de gobierno que se estableció en 1799 ya no mencionaba al superintendente entre los cargos que existían en la Misericordia. Por el contrario, en lo que respecta al mayordomo, este sí pervivió, y de hecho se decidió por mantenerle en su puesto, delegándole todos los asuntos relacionados con la vida diaria y, más concretamente, la gestión interna de la institución. Entre sus funciones, el mayordomo salía "todos los viernes a pedir limosna por la [calle de la] platería y la pescadería ${ }^{41}$. Asimismo, actuaba como una especie de ayudante de carcelero y vigilaba cualquier tipo de infracción o abuso entre los mismos pobres.

Desde los inicios de la Misericordia, una de las mayores preocupaciones en lo que se refería al porvenir de los pobres era su bienestar espiritual, así como el mantenimiento de un celo escrupuloso mientras residiesen allíi2. Y, para tal fin, se nombró a un eclesiástico que vigilaba su cumplimiento. Aunque esta figura recibió distintos nombres, la idea de un miembro del clero dentro de los hospicios fue una constante en todo el territorio español. En la Misericordia de Oviedo, como

38. La figura del mayordomo fue una constante en las casas de Misericordia, véase Alonso, Anna y RodríGuEz, Lluïsa. "Beneficència il-lustrada i iniciatives econòmiques», op. cit., p. 799.

39. AMP, Actas Municipales, AH 2107, f. 51 v.

40. Desde sus inicios, el Ayuntamiento de Palma elegía cada dos años a cuatro regidores encargados de todos los asuntos de la casa de Misericordia. Es plausible pensar que, en su afán por intentar revitalizar el hospicio, eliminasen la figura del superintendente, siendo esos cuatro regidores los encargados de la supervisión de la institución. ARM, Misericordia, M 1, p. 3.

41. ARM, Misericordia, M 1, p. 16.

42. ANZANO, Tomás. Elementos preliminares para poder formar un sistema de hospicio general. Madrid: Imp. Manuel Martín, 1778, p. 104. 
en muchas otras, el perfil que se precisaba para este cargo era el de «un sacerdote virtuoso, de competente edad, de costumbres irreprehensibles, que esté aprobado de confesor, y en quien se reconozca un carácter especial de celo" ${ }^{43}$. No eran requisitos exagerados, pues ejercía un papel trascendental dentro de la Misericordia, siendo él quien estaba en un contacto más directo con los pobres residentes.

En la mayoría de casas de Misericordia, este cargo recibió el nombre de capellán, si bien en la de Palma se le llamaba prior $^{44}$. Sus funciones, a fin de cuentas, no diferían demasiado de un hospicio a otro. A él se le delegaban tareas de muy diversa índole: primeramente estaban las propias del sacerdocio, como el oficio de misas en la iglesia del hospicio, la confesión de los allí residentes y «doctrinar a todos los pobres recogidos, y enseñarles la Doctrina Cristiana y Misterios de nuestra Santa Religión ${ }^{45}$. A continuación, ejercía funciones de dirección y administración, como la supervisión de las comidas o la visita de «las salas, cuidando de que las camas estén levantadas, procurando su limpieza y aseo, [...] evitando toda porquería que a más [de] ser impropia de esas casas, contribuye la limpieza y su salud ${ }^{46}$. Pero, además, el prior era el carcelero -junto con el mayordomo- de la Misericordia. Solo él permitía que los internos pudieran salir del hospicio, siempre con la aprobación de la junta. Y, por supuesto, era él quien aplicaba los castigos a los infractores y vigilaba el mantenimiento del buen orden y celo.

La mayoría de casas de Misericordia contaban con un único prior o capellán, que era admitido por lo general con una edad superior a los veinticinco años ${ }^{47}$. Sin embargo, en la de Palma, empezó a hacerse evidente que el prior necesitaba ayuda. Hacia 1782, el prior de entonces, el Dr. Juan Bautista Colom, escribió a los regidores municipales recalcándoles que tras la incorporación de más pobres al hospicio, «un solo eclesiástico no puede cuidarles completamente y dedicarse al aumento de los fondos y limosnas de dicha casa ${ }^{48}$. De ese modo, el Ayuntamiento consideró necesario contratar a un capellán que asistiese al primero en todas sus funciones. Con la introducción de esta figura, el prior se vio liberado de la carga que pesaba sobre sus hombros, y se le permitió pasar a vivir fuera del hospicio, dedicándose mayormente a la recolección de limosnas en la capital. Y, mientras tanto, el nuevo capellán «tendrá también la obligación de vivir en la

43. Biblioteca Pública de León (BPL), Ordenanzas de la Casa de Misericordia de Oviedo, Fondo Antiguo 1176, p. 46.

44. Véase BARrio Moya, José Luis. «El Real Hospital de la Misericordia de Madrid según un inventario de 1735". Anales del Instituto de Estudios Madrileños, 2011, 51, p. 142.

45. ARM, Misericordia, M 8, s/f.

46. ARM, Misericordia, M 8, s/f.

47. Alonso, Anna y Rodríguez, Lluïsa. "Beneficència il·lustrada i iniciatives econòmiques», op. cit., p. 802 .

48. ARM, Misericordia, M 8, s/f. 
misma casa para poder asistir con más puntualidad a las necesidades espirituales y temporales, y cuidar de su economía ${ }^{49}$.

El tiempo hizo a los regidores muy conscientes de la situación que se vivió: el nuevo capellán pasó a ejercer todas las funciones que antaño recaían en el prior, mientras este ya no se preocupaba más que por una supervisión indirecta y lejana de la Misericordia. Finalmente, cuando se implantaron las reformas en 1799, la nueva junta de gobierno consideró necesaria una implicación mayor por parte del prior, que debía retomar su papel de director de la Misericordia. Así que, lo primero que hizo la junta, fue confirmar la permanencia en el cargo del prior de entonces, "asegurada del celo y desinterés con que ha administrado hasta aquí los caudales de dicha casa, y del gusto con que se ha dedicado a su servicio» ${ }^{50}$. Pero además, reforzó sus atribuciones, obligándole a ejercer nuevamente un control férreo dentro de la Misericordia. Por su parte, el capellán se convirtió en una figura difusa, una especie de subalterno del primero. De hecho, en los libros de actas, este únicamente aparece mencionado en contadas ocasiones, y la mayoría de las veces se trata de cuestiones menores.

Junto a los anteriores, el hospicio disponía también de personal doméstico que contribuía al mantenimiento de la higiene y buen orden. Todos los hospicios tenían cocineras que alimentaban a los residentes. Sin dejar de lado los riesgos que corría la convivencia de hombres y mujeres en un mismo edificio, las casas de la Misericordia habían establecido una vida segregada, como ocurría con la de Oviedo, donde "conviene igualmente haya dos cocinas separadas, para los dos sexos ${ }^{51}$. Lo único que sabemos de la Misericordia de Palma es que contaba con un único cocinero que debía alimentar a todos los internos, suponiendo que eran los criados quienes se ocupaban de la distribución de la comida. Se tiene constancia de que, a finales del siglo XVIII, el hospicio tenía contratados a seis criados, que seguramente servían también al prior, al capellán y al mayordomo. De hecho, cuando Antonio Llabrés fue nombrado primer capellán en 1782, se le asignó «una criada que se le considera necesaria, a más de lo cual podrá usar lícitamente para sí y dicha criada de todos los comestibles de la casa ${ }^{52}$.

Por otro lado, los hospicios estaban concebidos como lugares de trabajo para los pobres que vivían allí, precisamente con la intención de «que se ocupen así los hombres como las mujeres en sus trabajos respectivos y a que estén dedicados, evitando la holgazanería, perjuicios a la casa y a ellos mismos "s3. Si esto era cierto, es lógico pensar que el hospicio tuviera maestros y maestras dedicados a formar a los pobres. Sin embargo, hasta la reforma de 1799, desconocemos la presencia de

49. ARM, Misericordia, M 8, s/f.

50. ARM, Misericordia, M 1, p. 15.

51. BPL, Ordenanzas de la Casa de Misericordia de Oviedo, Fondo Antiguo 1176, p. 25

52. ARM, Misericordia, M 8, s/f.

53. ARM, Misericordia, M 8, s/f. 
maestros dentro del hospicio, aunque no puede descartarse. De hecho, entre las informaciones que se presentaron para elaborar el famoso censo de Floridablanca, no hay registrados maestros, aunque es posible que sea porque no vivieran allí. Las primeras referencias las hallamos el mismo año de 1799, pues la nueva junta constató ya la presencia de dos maestras. En cuanto a maestros para hombres, hubo que esperar a los primeros años del siglo XIX ${ }^{54}$. A continuación, se adjunta la relación del personal que habitaba en la Misericordia, y que el prior envió al Ayuntamiento de Palma para elaborar el mencionado censo en 1787:

\begin{tabular}{|c|c|c|c|}
\hline \multicolumn{4}{|c|}{$\begin{array}{c}\text { PERSONAL DE LA CASA DE LA MISERICORDIA DISTRIBUIDO } \\
\text { EN FUNCIÓN DE OFICIOS Y RANGOS DE EDAD }\end{array}$} \\
\hline Cargo & 25 a 40 años & 40 a 50 años & TOTAL \\
\hline Prior/capellán & 1 & 1 & 2 \\
\hline Empleados & 2 & 0 & 2 \\
\hline Sirvientes & 3 & 3 & 6 \\
\hline
\end{tabular}

La Misericordia disponía también de personal agregado, que se ocupaba de la recolección de las limosnas, es decir, su sustento económico principal. Desde sus inicios, el hospicio tenía contratados dos cuestores que supervisaban toda la recolecta y coordinaban a los bacineros en las villas rurales de la isla. La figura de un cuestor se constató ya en Mallorca durante la Edad Media, pues algunos hospitales contaban con estas figuras para recaudar limosnas ${ }^{56}$.

Parece ser que, durante el siglo XVIII, la red de donativos que gestionaban los cuestores y bacineros no estaba siendo demasiado efectiva. Hacia 1723, los regidores municipales dudaban de la eficacia de los bacineros en su tarea pues, "si en altre temps enviaven almoinas, ara sols contribueixen en hospedar el questor ${ }^{57}$. Y por si esto no fuera suficiente, cuando la nueva junta programó la reforma de la Misericordia en 1799, consideró necesario "que deberían desterrarse [los cuestores], habituándoles en este cargo a varios particulares decentes por villas ${ }^{58}$. Las juntas de caridad terminaron llenando el vacío dejado por aquellos cuestores, que poco o nada habían contribuido al mantenimiento de la Misericordia durante más de un siglo.

54. ARM, Misericordia, M 1.

55. Véase Arxiu Diocesà de Mallorca (ADM), MSL/296, f. 34. Elaboración propia de tabla.

56. CONTRERAs MAS, Antonio. "Asistencia hospitalaria en Mallorca bajomedieval siglos XIII-XV". Medicina Balear, 2008, 23/2, p. 14.

57. ARM, Audiencia, Real Acuerdo, 666, s/f.

58. ARM, Misericordia, M 1, p. 17. 
3. ¿HOSPICIOS, FÁbricas O CÁRCELES? los POBRES DE la Misericordia Y SUS CONDICIONES DE VIDA

Hasta las reformas de 1799 , contabilizar el número de pobres que vivieron en la Misericordia ha sido difícil por varias razones ${ }^{59}$. En primer lugar, se han conservado muy pocos documentos del hospicio en el siglo XVII, especialmente en lo que se refiere al recuento de residentes. Al mismo tiempo, los libros de registros muestran que muchos de los pobres que entraban a la Misericordia morían a las pocas semanas o meses, seguramente por su precaria salud, además de las deficitarias condiciones higiénicas que presentaba el hospicio ${ }^{60}$. Asimismo, los regidores del Ayuntamiento de Palma tendían siempre a exagerar las cifras, precisamente para demostrar los supuestos buenos resultados que se estaban obteniendo, la mayoría de ellos ficticios. Por otro lado, estas cantidades fueron fluctuando en función, muchas veces, de las distintas sequías y hambrunas que azotaron la isla en momentos puntuales del Setecientos.

En un informe proporcionado por el obispo Pedro Rubio-Benedicto en 1780, este confirmaba que «al presente hay de 120 ó 150 pobres de ambos sexos recogidos, pero que este número era muy corto para la necesidad que le había parecido tenía aquel Reino» ${ }^{61}$. Pocos años después, con razón del censo de Floridablanca, el prior de la Misericordia registró el número de pobres que en aquel momento residían, diferenciándolos en función de su sexo y edad:

\begin{tabular}{|c|c|c|c|c|c|}
\hline \multicolumn{5}{|c|}{ POBRES ADULTOS RESIDENTES EN LA CASA DE MISERICORDIA DE PALMA } \\
\hline Sexo & 16 a 25 años & 25 a 40 años & 40 a 50 años & 50 -adelante & TOTAL \\
\hline Hombres & 1 & 5 & 8 & 61 & 75 \\
\hline Mujeres & 26 & 8 & 15 & 132 & 181 \\
\hline \multicolumn{5}{|c|}{ MENORES RESIDENTES EN LA CASA DE MisERICORDIA DE PALMA } \\
\hline Sexo & \multicolumn{2}{|c|}{ Hasta 7 años } & 7 a 16 años & TOTAL \\
\hline Niños & 4 & 16 & 20 \\
\hline Niñas & 6 & 23 & 29 \\
\hline
\end{tabular}

Si tenemos presentes las cifras ofrecidas en 1787, en el hospicio vivían más de trescientas personas. Como puede observarse, la mayoría eran mujeres mayores de cincuenta años, muchas de ellas viudas empobrecidas. Por lo mismo, algunos hombres ancianos que no disponían de recursos o habían sido abandonados por

59. DeyÀ BaUZÀ, Miquel. "L'assistència social a Mallorca", op. cit., p. 27.

60. Véase ARM, Misericordia, M 641.

61. BBM, Fondo del Convento de San Francisco, leg. 6, s/f.

62. Véase ADM, MSL/296, f. 34. Elaboración propia de tabla. 
sus familias, veían los hospicios como la única vía para asegurar su supervivencia $^{63}$. De modo que, a fines del siglo XVIII, precisamente en los momentos anteriores a la gran "cacería" de pobres, la Misericordia a menudo funcionaba como un lugar donde personas ancianas y desamparadas podían retirarse para vivir hasta que llegase el día de su muerte ${ }^{64}$. Pero la Misericordia también alojaba a niños y niñas pequeños, si bien en un número mucho menor ${ }^{65}$. Algunas veces eran los hijos de mendigos que habían pasado a vivir en el hospicio, y otras, niños huérfanos sin hogar. Debe tenerse en cuenta que la Casa Real de Expósitos no empezó a funcionar hasta 1798, en consonancia con las grandes reformas asistenciales que se estaban implantando en la Mallorca finisecular ${ }^{66}$.

Cuando se puso en marcha la reforma de la Misericordia en agosto de 1799, la cifra de pobres era muy similar a la de años anteriores. Las malas cosechas y la precariedad económica que se estaban viviendo habían empobrecido a muchas familias, que se veían faltas de recursos ${ }^{67}$. Parece ser que, ese mismo año, «el número de pobres que existen en ella [es] el de doscientos ochenta " ${ }^{68}$, si bien es cierto que en las calles la proporción de mendigos que se negaban a entrar en el hospicio era mayor: unos cuatrocientos.

En otro ámbito, una cuestión no menos importante era la tipología de pobres que podían acceder a vivir allí69. Ciertamente, en el siglo XVIII -como en épocas anteriores- existían dos clases bien diferenciadas de pobres. Por un lado, estaban los llamados pobres verdaderos, es decir, aquellos que, a causa de una enfermedad o por su avanzada edad, se veían imposibilitados de realizar un trabajo ${ }^{70}$. Para su supervivencia, la Corona había concedido durante muchos años las licencias

63. Durante el siglo XVII, el mantenimiento de los ancianos dependía enormemente de los lazos de solidaridad entre grupos. En el caso de las familias empobrecidas, era muchas veces la Iglesia quien ayudaba en su manutención o, en ocasiones, la misma familia si contaba con los medios suficientes. Sin embargo, hasta el siglo XVIII, no hubo un interés por parte del Estado por reformar los canales de beneficencia y ayudar a estos grupos sociales. Véase Martínez Ortega, Paz; Polo Luque, María Luz y Carrasco Fernández, Beatriz. "Visión histórica del concepto de vejez desde la Edad Media». Cultura de los Cuidados, 2002, 11, p. 43.

64. MAZa Zorrilla, Elena. Pobreza y asistencia social..., op. cit., p. 21.

65. Véase SÁNChez BAREA, Rafael Fermín. "La casa de Niños Expósitos en la Algeciras decimonónica: de la Miseria a la Junta Municipal de Beneficencia». En BERRUEzo AlBÉNIz, María Reyes y Conejero López, Susana (coords.). El largo camino hacia una educación inclusiva: la educación especial y social del siglo XIX a nuestros días. Pamplona-Iruñea: Universidad Pública de Navarra, 2009, vol. 2, pp. 349-356.

66. Véase CORTÉs, Bartomeu. La Reyal Casa General d'Expòsits de Mallorca. Monografia bistórica (1798-1842). Palma: Tipografía Provincial, 1928.

67. Bejarano Galdino, Emilio. Amotinamientos populares y revuelta de los privilegiados en Mallorca a fines del siglo XVIII. Palma: El Tall, 2000, p. 55.

68. ARM, Misericordia, M 1, p. 2.

69. Véase CARASA Soto, Pedro. "Cambios en la tipología de pauperismo en la crisis del Antiguo Régimen». Investigaciones Históricas: Época Moderna y Contemporánea. 1987, 7, pp. 131-150.

70. Ramos VÁzQuez, Isabel. "Policía de vagos para las ciudades españolas", op. cit., p. 244. 
necesarias para que pudiesen pedir limosnas, quedando adscritos a unas zonas concretas de las ciudades. Por otro lado, se hallaban los falsos pobres, que "satisfacen el hambre sin los afanes del trabajo que totalmente aborrecen, para el que están aptos por más que se presenten tullidos, [...] pues todas las penalidades de estos accidentes es producto de la malicia y efecto de una desordenada invención ${ }^{71}$. Todo pobre que ingresase en la Misericordia, debía pasar primero por la inquisitiva mirada del prior y, de hecho, durante siglos, solo los "verdaderos» podían entrar allí.

Pero cuando Carlos III y sus ministros prepararon el gran recogimiento de pobres a partir de 1781, el abanico se volvió mucho más amplio. La idea cambió de tal modo que todos los pobres sin excepción debían vivir en el hospicio, y una vez dentro, en palabras de Tomás de Anzano, "es posible y muy conveniente el escrutinio de los falsos y verdaderos, de los legítimos e ilegítimos impedidos ${ }^{{ }^{2}}$. Cada vez que una persona solicitaba entrar en la Misericordia, la junta de gobierno exigía un informe al prior, y solo con su beneplácito, se decidían a admitirla. No fueron pocos los casos en que un pobre quedó a las puertas del hospicio, por ser considerado una influencia nociva para sus compañeros. Por ejemplo, en 1799, una mujer que había tenido un hijo antes de casarse y lo había abandonado en la Casa de Expósitos no fue aceptada en la Misericordia, "considerando que no conviene una mujer de semejantes circunstancias, que luego se sabrían en la casa por personas que es mejor las ignoren ${ }^{73}$.

Un verdadero quebradero de cabeza para las juntas de gobierno de las casas de Misericordia era el asunto de los matrimonios. ¿Podían acceder al hospicio parejas casadas? En muchas ocasiones, una familia había sucumbido a la ruina y se veía forzada a vivir de la caridad para poder sobrevivir. De hecho, las terribles hambrunas que azotaron Mallorca en diferentes momentos, especialmente a finales del siglo XVIII, se habían traducido en un aumento de estas escenas ${ }^{74}$. Pues bien, existían varias circunstancias que dificultaban el ingreso de los matrimonios. Anzano ya alertaba sobre la "gran discreción en admitir casados en los Hospicios, [...] y mucho más en que se casen en la reclusión» ${ }^{75}$. Puesto que las casas de Misericordia funcionaban como centros segregados, se consideraba más prudente «que no duerman juntos respecto de que no hay por ahora en la casa comodidad que lo permita ${ }^{76}$.

71. Campillo y Cossío, José del. Lo que hay de más y de menos en España para que sea lo que debe ser y no lo que es. Barcelona, 2005, p. 83.

72. ANZANO, Tomás. Elementos preliminares para poder formar..., op. cit., p. 65.

73. ARM, Misericordia, M 1, p. 84.

74. CAMPANER Y FUERTES, Álvaro. Cronicón Mayoricense. Noticias y relaciones bistóricas de Mallorca desde 1229 a 1800. Palma: Ajuntament de Palma, 1984, p. 540.

75. ANZANO, Tomás. Elementos preliminares para poder formar..., op. cit., p. 120.

76. ARM, Misericordia, M 1, p. 138. 
Pero más difícil de tratar era cuando un miembro del matrimonio pasaba a vivir en el hospicio. Algunas veces, se daban casos de mujeres pobres que se refugiaban en los hospicios para huir de matrimonios desgraciados ${ }^{77}$. Por ejemplo, en 1800, Isabel Azorín se presentó en la Misericordia de Palma rogando al prior que "se la admita en esta casa para vivir libre del maltrato que sin motivo le da su marido ${ }^{78}$. En dichas ocasiones, las mujeres solo podían ingresar en el hospicio con permiso expreso del esposo, y aun entonces, se advertía "que por ningún pretexto viniese [el marido] a alborotar ni incomodar como lo han hecho otros viniendo en esta casa sus mujeres ${ }^{79}$.

El día a día en una casa de la Misericordia estaba totalmente reglamentado. Desde su ingreso, los pobres debían abrazar el modo de vida que las constituciones del hospicio habían diseñado para ellos. Para su total cumplimiento, el prior vigilaba con celo y mano de hierro que así fuera: «Procurará y velará, se ocupen así los hombres como las mujeres en sus trabajos respectivos y a que estén dedicados, evitando la holgazanería, perjuicios a la casa y a ellos mismos ${ }^{80}$. Los pobres compartían habitaciones, diferenciándose entre hombres y mujeres. Sin embargo, hasta 1799, el espacio siempre era insuficiente, pues, como ocurría también en la Misericordia de Barcelona, "los recogidos están sumamente incomodados, durmiendo de dos en dos, y a veces en mayor número de que se siguen aquellas consecuencias que sin repetirlas prevería el Consejo» ${ }^{81}$. Pero, además, las condiciones higiénicas no eran las más adecuadas, siendo «muy necesario [que] se haga un cuarto para separar los muchachos enfermizos de los sanos ${ }^{82}$. Ciertamente, las reformas que se proyectaron paliaron ligeramente esta situación, enviando a los enfermos leves a habitaciones separadas y destinando a aquellos con enfermedades graves al Hospital General.

Cada mañana, los pobres allí residentes debían hacerse su cama y ayudar en la limpieza de las habitaciones. La nueva junta de gobierno tuvo especial preocupación por el «cuidado así cristiano como político, particularmente a los menores para que algún día sean útiles al estado» ${ }^{83}$. La consideración por el porvenir de los niños creció enormemente durante aquella etapa y, de hecho, el prior tenía la tarea de vigilar su evolución espiritual y material, instruyéndoles en el catecismo,

77. Sobre el tema del maltrato conyugal y la violencia familiar, véase ORTEGA LóPEz, Margarita. "Violencia familiar en el pueblo de Madrid durante el siglo XVIII". Cuadernos de Historia Moderna, 2007, 31, pp. 7-37.

78. ARM, Misericordia, M 1, p. 211

79. ARM, Misericordia, M 1, p. 211

80. ARM, Misericordia, M 8, s/f.

81. AHN, Consejos, L. 1952, f. 261.

82. ARM, Misericordia, 1, p. 30.

83. ARM, Misericordia, M 8, s/f. 
enseñándoles las primeras letras y, especialmente, instando «a que se limpien por la mañana, pues el ser pobres no es incompatible con el asco ${ }^{84}$.

Mediante el toque de campana, se llamaba a todos los pobres a misa, que el prior o el capellán oficiaban en la iglesia del hospicio. Algunas casas de Misericordia se preocuparon de respetar este ambiente de segregación, como es el caso de la casa de Oviedo, donde "las mujeres y niñas oigan misa y recen el Rosario desde los corredores [...], y los hombres y muchachos entrarán por la puerta principal para ocupar y acomodarse en el piso y pavimento de ella ${ }^{85}$. Tras la misa, el prior supervisaba el reparto de pan a los internos, vigilando siempre que no se produjesen disputas o altercados. A continuación, hombres y mujeres se dedicaban a los trabajos que se les habían asignado y, mientras tanto, el prior revisaba personalmente las habitaciones, "procurando su limpieza y aseo, y no permitiendo se haga en ellas fuego ni se pongan imágenes en las paredes» ${ }^{86}$.

Sin lugar a dudas, la seguridad dentro del hospicio era uno de los asuntos prioritarios para sus autoridades. Antes de la reforma de 1799, la casa de la Misericordia no disponía de los recursos necesarios para evitar las disputas y abusos que, a menudo, se vivían entre los mismos residentes. La falta de habitaciones había sido un problema muy serio, que podía traducirse incluso en abusos sexuales. Los galanteos, especialmente entre jóvenes, eran cosa habitual en el día a día. Por ello, el prior vigilaba de cerca el contacto entre hombres y mujeres. Sin embargo, la mala distribución del edificio dificultaba este ambiente segregado, «teniendo que pasar [los muchachos] por otros cuartos en donde habitan varias muchachas» ${ }^{87}$. La ampliación del edificio en 1799 pretendía establecer una mejor distribución del espacio y un control más efectivo.

A todo lo anterior se le sumaba el que sin duda era el mayor problema dentro del hospicio: el alcohol. Como Tomás de Anzano escribía, «un hombre poseído de este vicio es jurador, blasfemo, maldiciente, obsceno, asesino, incendiario y autor de cuantas atrocidades puede cometer ${ }^{88}$. Ciertamente, los problemas de alcoholismo fueron una constante, y ocasionaron escenas realmente desagradables. Aunque estaba prohibido el consumo de bebidas alcohólicas dentro de la Misericordia, a menudo los internos conseguían hacerse con una botella. Y era entonces cuando llegaban los incidentes. Por ejemplo, se dio el caso de una mujer que "siempre que se halla tomada del vino, desboca en liviandades, habla deshonestamente, y hace acciones torpes ${ }^{89}$. No fue un caso aislado. Y como las casas de Misericordia, especialmente durante el último tercio del siglo XVIII, no estaban ya consideradas para funcionar como centros correccionales, estos sujetos eran

\footnotetext{
84. ARM, Misericordia, M 8, s/f.

85. BPL, Ordenanzas de la Casa de Misericordia de Oviedo, Fondo Antiguo 1176, s/f.

86. ARM, Misericordia, M 8, s/f.

87. ARM, Misericordia, M 1, p. 71.

88. ANZANO, Tomás. Elementos preliminares para poder formar..., op. cit., p. 120

89. ARM, Misericordia, M 1, p. 83
} 
a menudo expulsados del hospicio. Sin embargo, esto no quiere decir que no se aplicasen castigos a los internos. Precisamente porque, aún a finales del Setecientos, las casas de Misericordia no habían podido librarse todavía de un aura carcelaria. Todo ello, pese a los desesperados intentos por parte de los ministros ilustrados por dar un toque de barniz a aquellas instituciones, especialmente en lo que se refería a convertirlas en auténticos centros de control social y también de producción.

Ciertamente, fue bajo el reinado de Carlos III cuando la Corona programó una batería de reformas en el ámbito asistencial, y en lo que a los hospicios se refiere, decidió sacarles mayor provecho ${ }^{90}$. Ministros como Floridablanca veían estas instituciones como centros que podían ofrecer un gran servicio al Estado ${ }^{91}$. De hecho, las casas de Misericordia que se proyectaron durante esta época -tanto las que se reformaron como las de nueva planta- asumieron una doble función: por un lado, se configuraron como centros donde internar a los pobres, que por entonces eran concebidos como elementos incómodos e inútiles ${ }^{92}$. Pero, al mismo tiempo, estas casas se convirtieron también en fábricas de producción -o esa era la idea de base-, rentabilizando económicamente dichas instituciones.

Los allí internos se dedicaban a distintas labores que justificaban su permanencia, y como decía la junta de la Misericordia de Barcelona, "se verían empleadas muchas manos que gimen en la ociosidad y en el crimen ${ }^{93}$. Los trabajos destinados a los pobres solían ser los mismos en las distintas casas de Misericordia, y mediante su producción se planeaba obtener ingresos que contribuyesen a la financiación del hospicio. En Oviedo, las mujeres se dedicaban al tejido de productos de lana y lino, "tal como el que usa la gente del campo de este Principado, Reino de León, confines de Galicia y montañas de Santander ${ }^{94}$. En el caso de Valencia, se ha constatado la existencia de un ramo de fábrica de cintas de seda ${ }^{95}$, y en Barcelona eran instruidas también en el tratado de la lana. Asimismo, en Palma, las mujeres «trabajan en hilar lino, cáñamo, algodón y lana, y hacen calcetas y cintas ${ }^{96}$. De hecho, el hospicio contaba con dos maestras que las adiestraban en estas tareas.

90. Helguera Qujada, Juan. "Asistencia social y enseñanza industrial en el siglo XVIII: el Hospicio y las Escuelas-fábricas de Alcaraz, 1774-1782». Investigaciones Históricas: Época Moderna y Contemporánea, 1980, 2, p. 73.

91. Véase Ruiz ABellán, M. ${ }^{a}$ Concepción. "La política asistencial del conde de Floridablanca". Monteagudo, 1980, 70, pp. 17-22.

92. Sobre el control social y la "clausura» de pobres en estos hospicios, véase FoucAult, Michelle. Vigilar y castigar. El nacimiento de la prisión. Buenos Aires: Siglo XXI, 1975, pp. 175 y ss.

93. AHN, Consejos, L. 1952, f. 261v.

94. BPL, Ordenanzas de la Casa de Misericordia de Oviedo, Fondo Antiguo 1176, s/f.

95. Biblioteca Valenciana Digital (BIVALDI), Establecimiento de un fondo para acopios de la Real Casa de Misericordia de Valencia, BV Gregorio Mayans, XVIII/494, 18, s/f.

96. ARM, Misericordia, M 1, p. 110. 
Por otro lado, los hombres considerados "hábiles», es decir, aquellos que eran capaces de ejercer un oficio, también se destinaban a tareas de diversa índole. En 1799, la junta de gobierno constató que, habiendo «en esta casa hombres robustos y ociosos, cuyo número aumentaba probablemente de cada día, era muy del caso pensar en darles alguna ocupación útil a sí y al hospicion ${ }^{97}$. Las autoridades de las casas de Misericordia consideraban un asunto urgente mantener ocupado a este sector, especialmente a los hombres jóvenes que allí residían.

Tras las oportunas reformas de 1799, el hospicio de Palma planteó seriamente instalar una serie de fábricas y talleres. En este caso, "los hombres se ocupan en la construcción de sogas de esparto cuya obra da algún lucro a la casa» ${ }^{98}$. Sobre si contaban con maestros que les instruyesen, hasta principios del siglo XIX no hay evidencias de ello. Además, todo parece indicar que estas fábricas no sacaban el máximo provecho posible. A las propias limitaciones de infraestructura, se sumaba la precaria calidad de los productos, que no podían competir en los mercados. Y por si esto no fuese suficiente, muchas veces, las autoridades del hospicio tenían problemas para supervisar que los pobres cumpliesen adecuadamente con sus tareas.

Por otro lado, los jóvenes tenían distintas ocupaciones dentro del hospicio. Algunos salían del mismo para servir en alguna casa que los admitiera, y, mientras tanto, aquellos que mostraban mejores aptitudes eran enviados a los gremios como aprendices ${ }^{99}$. El problema, muchas veces, era que los muchachos del hospicio se negaban a ser admitidos como tales, por lo que la junta estableció que "si no se encartan [los jóvenes] según las ordenanzas gremiales, se les llevará a la cárcel, y se hará pagar una pena o multa a los maestros que los tengan sin aquella circunstancia ${ }^{100}$.

En cuanto a los sectores considerados «inhábiles» para ejercer un trabajo, la Misericordia también tenía reservadas unas tareas para ellos. Niños, ancianos y personas con alguna minusvalía o enfermedad, salían a las calles para pedir limosna -cuyos beneficios iban directamente al caudal de la institución- o asumían "las obligaciones precisas de la casa y del carretón que mantiene para recoger los animales muertos de las calles ${ }^{101}$. De modo que la vida en las casas de Misericordia estaba pautada al detalle, y cada uno de los que allí vivían debía cumplir con sus obligaciones. En caso de no hacerlo, las constituciones del hospicio también contaban con una lista de castigos.

A lo largo de la Edad Moderna, las casas de Misericordia conservaron siempre una estela carcelaria. Aunque jamás habían sido concebidas como prisiones,

97. ARM, Misericordia, M 1, p. 102.

98. ARM, Misericordia, M 1, p. 109.

99. Deyà BaUŻ̀, Miquel. "Assistència social a Mallorca", op. cit., p. 27.

100. ARM, Misericordia, M 1, p. 210.

101. ARM, Misericordia, M 1, p. 109. 
eran muchos los que las miraban de tal modo, "con motivo de que en las condenas de los Tribunales se continuaba nombrando el Hospicio como destino de delincuentes ${ }^{102}$. En efecto, a lo largo del siglo, estas instituciones admitieron también a infractores de la ley o prostitutas, que eran aislados y severamente castigados. Esta circunstancia terminó modificándose durante los últimos años del reinado de Carlos III, pero lo cierto es que tratadistas como Valentín Foronda siguieron considerándolas como "magníficas cárceles decoradas con el hermoso nombre de Casas de Misericordia ${ }^{103}$. De hecho, aquella fama no era del todo inmerecida.

En las constituciones de muchas casas de Misericordia, los castigos a los internos estaban incluidos, quedando estipulado el tipo de corrección que se merecían por cada falta. Tomás de Anzano alertaba ya de los peligros que tenía un castigo abusivo. Menospreciando, quizás, la naturaleza de los pobres, el tratadista defendía que "las penas corporales las miran muchas veces como propias de su espíritu y esfuerzo; y lejos de temerlas, hacen alarde de sufrirlas» ${ }^{104}$. Pero lo cierto es que muchas casas de Misericordia eran famosas por aplicar castigos contumaces. Una primera prueba de ello está en el hecho de que contaban con una sala propia para la corrección. Por ejemplo, la casa Oviedo tenía una habitación en el subsuelo del edificio, donde había «un cepo para detener a los vagabundos forasteros, [...] y a fin de mortificar a los pobres inquietos, sediciosos, provocativos, a los que no trabajaren en el día de la labor ${ }^{105}$. La casa de la Misericordia de Zaragoza era una verdadera prisión, que disponía de calabozo, donde se daban castigos tales como la privación de comida o los azotes ${ }^{106}$. Y la Misericordia de Valladolid contaba con "cuartos para detenidos", en el que se retenía a los infractores ${ }^{107}$.

Como se viene diciendo, los castigos eran diversos y variaban en función de la falta. La Misericordia de Cádiz estableció en sus constituciones que "los castigos y correcciones que se dieren a los niños y demás pobres por sus faltas domésticas, o su desidia en los trabajos, sean proporcionadas a ellas y correspondientes a sus edades ${ }^{108}$. Y, en efecto, aunque estos hospicios no estaban diseñados como casas de corrección, y los pobres más conflictivos eran inmediatamente expulsados o enviados a prisión, el castigo era parte importante en el día a día de la Misericordia.

102. ARM, Audiencia, Reales Órdenes 1785-1787, 579, s/f.

103. Foronda, Valentín. Miscelánea o colección de varios discursos. Madrid, 1793, p. 37. Cit. por Ramos Gorostiza, José Luis. "Joseph Townsend y la cuestión de los pobres en la España ilustrada». Dieciocho, 2013, 36, p. 128.

104. ANZANO, Tomás. Elementos preliminares para poder formar..., op. cit., p. 120.

105. BPL, Ordenanzas de la Casa de Misericordia de Oviedo, Fondo Antiguo 1176, s/f.

106. Gómez URDÁÑEz, José Luis. "La Real Casa de Misericordia de Zaragoza: cárcel de gitanas (1752-1763)». En Sobaler Seco, María de los Ángeles y García Fernández, Máximo (coords.). Estudios en homenaje al profesor Teófanes Egido. Valladolid: Junta de Castilla y León, 2004, vol. I, p. 6.

107. Palomares IbáÑEz, Jesús María. La asistencia social en Valladolid..., op. cit., p. 216.

108. Biblioteca Pública de Cádiz (BPC), Ordenanzas para el gobierno de la Casa de la Misericordia de la ciudad de Cádiz, XVIII-3454, p. 35. 
La mayoría de las veces, el motivo para imponer un castigo se debía a la infracción del orden o el incumplimiento de la rutina diaria.

Cuando, por ejemplo, un pobre se negaba a trabajar, se le podía privar de alimento durante un día o encerrarle en un cuarto de aislamiento. Del mismo modo, cuando un interno alteraba el orden, ya fuese porque estuviera ebrio o se enzarzase en una pelea, se le solían poner los grilletes. Por ejemplo, en la Misericordia de Palma, se dio el caso de una mujer alcohólica que protagonizaba escenas violentas con otros internos, "no bastando para contenerla amenazas, encierros, ni guillos ${ }^{109}$. Solo cuando la junta de gobierno comprobó que nada era suficiente, y que «no pueden las Justicias enviar, destinar ni condenar a persona alguna a los hospicios» ${ }^{110}$, se decidió por expulsarla.

El prior de la Misericordia de Palma fue especialmente severo con las jóvenes que salían a servir a las casas cercanas al hospicio. Cuando, en agosto de 1800, el prior constató que algunas muchachas eran «insolentes con sus amos en términos que a la menor corrección u aviso ya les amenazan", consideró seriamente el hecho de expulsarlas, aunque finalmente se decidió por «no darlas pan, sino la sopa y cama ${ }^{111}$. La idea que subyace aquí es, precisamente, que las casas de Misericordia repetían las dinámicas de control social tan propias de la sociedad del siglo XVIII. Los pobres debían amoldarse al modo de vida que la Corona había diseñado para ellos, adaptándose a unas condiciones laborales impuestas y esforzándose por regresar a una sociedad que habían abandonado voluntaria o forzadamente. Y, en este sentido, los castigos eran considerados como una medicina necesaria para abandonar las prácticas aborrecibles.

\section{CONCLUSIONES}

La pobreza fue una cuestión siempre pendiente a lo largo de la Edad Moderna. La existencia de casas de Misericordia solo es entendible si tenemos presente la importancia que se le dio al problema de los pobres y qué debía hacerse con ellos. En Palma, la fundación de la casa de Misericordia en 1677 intentó paliar este asunto, pero durante mucho tiempo no lo consiguió. Como se ha mostrado, hasta la reforma de 1799, aquel hospicio vivió en un estado decadente, siempre pendiente de renovaciones y sin medios para vivir holgadamente. El espacio era insuficiente para alojar a los pobres, las instituciones de poder parecían haberse olvidado de su misión asistencial, y las condiciones sociales y económicas que vivió Mallorca durante la segunda mitad de la centuria únicamente incrementaron los niveles de pobreza, complicando todavía más las cosas.

109. ARM, Misericordia, M 1, p. 83.

110. ARM, Misericordia, M 1, p. 83.

111. ARM, Misericordia, M 1, p. 209. 
Desde sus inicios, la Misericordia contó con unas constituciones y un personal doméstico dedicado al cuidado del edificio y del orden social allí dentro. Hasta finales del Setecientos, el Ayuntamiento de Palma mantuvo un control superficial de la institución, relegando su gobierno a cuatro regidores que se iban turnando cada dos años. Mientras la figura del superintendente, que había nacido con el mismo hospicio, finalmente desapareció, el mayordomo perduró en el tiempo y se mantuvo intacto. Por otro lado, el gobierno espiritual estuvo en manos de un prior, ayudado desde 1782 por un capellán. Ambos se ocupaban de vigilar el celo y buenas prácticas dentro de la Misericordia. Sin embargo, todo indica que la vida allí dentro no era sencilla. Como el espacio era insuficiente, el prior tenía problemas para vigilar el ambiente segregado que se esperaba de una casa de Misericordia. Asimismo, la red de donativos era muy irregular, y los cuestores contratados para organizar el envío de limosnas al hospicio no hacían del todo bien su trabajo.

Cuando se creó la nueva junta de gobierno en 1799, fueron muchos los cambios que se produjeron. Primeramente, la junta se ocupó de la supervisión directa de la Misericordia. Con esto, el prior asumió una ascendencia todavía mayor dentro del hospicio. A partir de entonces, no solo se ocupó del porvenir espiritual de los internos, sino que de él dependía el día a día de la Misericordia. Ayudado por el mayordomo y por el capellán, el prior tenía la última palabra y solo respondía ante la junta de gobierno. Él supervisaba todas las actividades que se desarrollaban en el recinto, instruía a los menores, oficiaba misa en la iglesia, y castigaba a los infractores. De modo que es inevitable considerar el excesivo poder que las juntas de gobierno delegaban en la figura del prior -o también llamado capellán en otras casas de Misericordia-. Pues, como la junta gobernaba en la distancia, los informes enviados por el prior solían ser siempre bien vistos y aceptados sin discusión.

En otro ámbito, como se ha mostrado, durante los siglos XVII y XVIII no todos los pobres eran admitidos en las casas de Misericordia. Estos hospicios habían nacido para alojar a los considerados "verdaderos pobres», es decir, aquellos que por sus circunstancias se veían en la miseria y no podían trabajar. Los ancianos o discapacitados veían en estos centros un lugar donde poder sobrevivir hasta el día de su muerte. Sin embargo, cuando Carlos III ordenó el recogimiento masivo de pobres en estas instituciones, el abanico se volvió mucho más amplio. A partir de entonces, las autoridades civiles y religiosas se preocuparon por encerrar a todos los pobres y, una vez dentro, se analizarían sus circunstancias para mantener allí a los verdaderos pobres, enviando a los falsos a otros destinos, como, por ejemplo, las filas del ejército.

La vida de aquellas gentes estaba totalmente reglamentada al detalle, y como la Corona pretendía extraer cierto provecho de aquellos hospicios, era indispensable que los pobres, tanto mujeres como hombres, se dedicasen a una actividad económica concreta durante su reclusión. Aparecieron así verdaderas fábricas donde se elaboraban productos que después se vendían, obteniendo ingresos directos para el mantenimiento del hospicio. Responder a la pregunta de si estas 
fábricas obtenían o no verdaderos beneficios económicos no es un asunto sencillo. Todo parece indicar que no era así. La misma casa de Misericordia de Palma tardó en contar con una infraestructura eficiente, faltando todavía telares durante los últimos meses de 1799. Además, la calidad de aquellos productos era, muchas veces, poco competitiva en los mercados. Y por si esto no fuera suficiente, a menudo era difícil para las autoridades de la Misericordia controlar que los internos realizasen bien su tarea. Precisamente aquí aparecía la cara más oscura de estos centros: los castigos.

Desde su nacimiento, las casas de Misericordia habían contado con un aura de presidio. Aunque no habían sido concebidas técnicamente como prisiones, muchas veces eran enviados allí delincuentes o mujeres licenciosas para su corrección. Y aunque Carlos III ordenó que terminasen estas prácticas, los hospicios siguieron manteniendo estancias destinadas específicamente al castigo y al tormento. Siempre que un pobre infringía una norma o se revelaba a las órdenes del prior, era castigado. Unas veces, se le ponían grilletes, otras quedaba aislado temporalmente o puesto en un potro, e incluso se le retiraba el alimento durante días. Y aunque los tratadistas del siglo XVIII recomendaron cautela a la hora de castigar, contamos con ejemplos sobrados de que los pobres eran severamente aleccionados, y se utilizó la violencia para acallarlos.

En definitiva, la idea que se desprende es que las casas de Misericordia funcionaron siempre como instituciones destinadas al recogimiento de los pobres, considerados como elementos «inútiles» a los intereses del Estado. Durante el último tercio del Setecientos, muchos de estos centros mejoraron su situación y se adaptaron mejor a las políticas higiénicas y sociales que propugnaban los ministros ilustrados. De hecho, la Misericordia de Palma experimentó mejoras importantes tras su reforma de 1799, ampliando el edificio, modernizando sus estancias y persiguiendo una situación relativamente cómoda para los internos. Sin embargo, al mismo tiempo, esa imagen decadente jamás abandonó dicha institución. Los cambios propugnados no terminaron de resolver los eternos problemas de la Misericordia, como era su financiación o los beneficios que podían obtenerse de sus fábricas. De modo que, durante el siglo XIX, todavía eran muchos los que se cuestionaban la verdadera eficacia de las casas de Misericordia. 